Sharif University of Technology
Scientia Iranica
SCIENTIA
I RAN I CA
http://scientiairanica.sharif.edu

\title{
Numerical analysis and monitoring of an embankment dam during construction and first impounding Case study: Siah Sang Dam
}

\author{
M. Rashidia,*, M. Heidari ${ }^{\mathrm{b}}$, and Gh. Azizyan ${ }^{\mathrm{b}}$ \\ a. Department of Civil Engineering, Sharif University of Technology, Tehran, Iran. \\ b. Department of Civil Engineering, University of Sistan and Baluchestan, Zahedan, Iran. \\ Received 12 October 2015; received in revised form 30 August 2016; accepted 12 November 2016
}

\author{
KEYWORDS \\ Earth dams; \\ Initial impounding; \\ Numerical modeling; \\ Instrumentation; \\ Vertical displacement; \\ Stress.
}

\begin{abstract}
Monitoring embankment dams is of crucial importance. In earth dams, the pore pressures, earth pressures, and displacements occurring during construction and function are measured at the time of the first impounding and exploitation by installing essential instruments, and so the dam's performance is evaluated and analyzed. Scope of the present research is the evaluation of Siah-Sang Dam performance through the results of instruments and back analysis, conducted by FLAC software. The Mohr-Coulomb elasticplastic model has been considered as the behavioral model of the dam, and the effect of the upstream shell's materials deformation has been modeled at the time of the initial impounding. Following that, comparing the results of the numerical analysis with the measured values indicates that there is a proper consistency between these two values. Moreover, it was observed that the dam's performance was suitable regarding the created pore water pressure, displacements, and stresses in the construction period as well as during the first impounding. In addition, susceptibility of the hydraulic fracturing was assessed by calculating the arching ratio. It was concluded that this dam is secure in comparison with the behavior of other similar dams in Iran and the world.

(C) 2018 Sharif University of Technology. All rights reserved.
\end{abstract}

\section{Introduction}

Geotechnical structure designers are concerned with different kinds of anisotropic and heterogeneous materials, which have complex and unstable behavior and geometric characters. Designers select these elements and behavior parameters because they are important in planning and analyzing the steps. Monitoring is very important because determination of exact stone, soil,

* Corresponding author. Fax: +98 5433447092 E-mail addresses: Mrashidi26@alum.sharif.edu(M. Rashidi); M.heidari12@yahoo.com (M. Heidari); Gh.azizyan@eng.usb.ac.ir(Gh.Azizyan).

doi: $10.24200 /$ sci. 2017.4181 and earth dam characteristics is very difficult. The behavior evaluation is achieved by installation of a device called instrument. Monitoring and instrumentation consider structure action during building and utilization and adaption with predicted time. Different factors, such as liquefaction, pitched roof slippage, and piping affection complexity of soil behavior, are required to install a determining device in important and critical places in order to consider and evaluate soil forces and structure deformations. This device is called instrument in the technical literature to observe the actual behavior and prevent any failure caused by different factors; so, dam's continuous monitoring is necessary. We use exact device to read data in different periods and evaluate data behavior. A back analysis is used to determine and reject instability factors. 
Duncan [1] and Kovacevic [2] are the recent main references on the state of the art in finite-element analyses applicable to the deformation behavior of embankments, mainly zoned rockfill dams. They discussed the methods of analysis, their limitations, available constitutive models of the stress-strain relationship, and areas of uncertainty. As Duncan pointed out, most analyses from the literature are Class C1 according to Lambe [3], i.e. after the event which may account for the generally good agreement between the predicted and observed deformation behaviors.

An important component of the modelling of embankment dams is the consideration of collapse vertical displacement of susceptible rockfills and earthfills in wetting. The effects of collapse vertical displacement are mostly noted for the upstream shoulder on initial impoundment, but collapse vertical displacement has also been observed in the downstream shoulder, following wetting due to rainfall, leakage or tail-water impoundment. Incorporating collapse vertical displacement into constitutive models adds further complexity and greater uncertainty to the estimation of material parameters between laboratory and field conditions due to the dependency of collapse vertical displacement on compaction moisture content, compacted density, applied stress conditions, and material properties. Justo [4] and Naylor [5] proposed methods for the incorporation of collapse vertical displacement of rockfill into constitutive models. The analysis of Beliche Dam, i.e. a central core earth and rockfill dam, by Naylor [6] is an example where collapse vertical displacement of the upstream rockfill is considered in the modelling.

The effect of pore water pressure dissipation in earthfills during construction was also considered by a number of authors, including Eisenstein and Law [7] in modelling Mica Dam and by Cavounidis and Höeg [8], amongst others. For these cases, the incremental embankment construction was modeled as a two-stage process: the first-stage modelling of a new layer construction using undrained properties for the core; the second-stage modelling of pore water pressure dissipation. In most cases, pore water pressure development in the core is ignored though. For wet placed earthfills, where high pore water pressures are developed during construction, the core is often modelled using undrained strength and compressibility parameters, and the permeability is assumed sufficiently low so that pore water pressures will not dissipate during the period of construction. In addition, Zumr et al. [9] investigated the solution based on transient simulation of seepage on earth dam through protection. Simulations were carried out by a two-dimensional numerical model based on Richards' equation for water flow in a porous medium. It has been shown that the proposed approach is suitable for large-scale engineering applications.

This paper first introduces the Siah Sang Dam, Kurdistan, Iran, and reviews the results of monitoring the instruments installed on the dam. Then, it introduces numerical back analyses of the dam for the end of construction and the first impounding loading. Finally, this study presents the results of the analyses and compares them with the monitoring results.

\section{Rock-fill Siah Sang Dam}

\subsection{General characteristics}

Siah Sang Dam is 33 meters high, the length of the crest is 352 meters, and the volume of the container is approximately 255,000 square meters. The dam is an earth dam with a clay core located in Kurdistan province in Iran. To make a graph of the dam's behavior, accurate instruments were chosen in 3 sections including piezometers, total soil mass pressure measurement cells, and vertical displacement meters and inclinometers which were installed within them. Taking into account the foundation type, height of the earth-fill dam, and depth of the valley, the most critical cross-section of Siah Sang Dam regarding the accumulation of pore water, maximum vertical displacement, and tolerance is the profile located in $0+175$ kilometers. The evaluation and numerical analysis will be done in this profile in this study. In addition, the material properties used in the numerical analysis were extracted from certain soil mechanical laboratory tests on the fine and coarse materials of the dam. Table 1

Table 1. Initial amounts of material parameters in the body of the dam.

\begin{tabular}{cccccccc}
\hline $\begin{array}{c}\text { Elements } \\
\text { parameters }\end{array}$ & $\begin{array}{c}\text { Dry unite } \\
\text { weight } \\
\left(\mathbf{k N} / \mathbf{m}^{\mathbf{3}}\right)\end{array}$ & $\begin{array}{c}\text { Inner friction } \\
\text { angle } \\
(\mathbf{d e g r e e})\end{array}$ & $\begin{array}{c}\text { Cohesion } \\
\mathbf{( k P a )}\end{array}$ & $\begin{array}{c}\text { Elasticity } \\
\text { module } \\
\mathbf{( M P a})\end{array}$ & $\begin{array}{c}\text { Poisson } \\
\text { coefficient }\end{array}$ & $\begin{array}{c}\text { Dilation } \\
\text { angle } \\
(\mathbf{d e g r e e})\end{array}$ & $\begin{array}{c}\text { Permeability } \\
\text { coefficient } \\
(\mathbf{m} / \mathbf{s})\end{array}$ \\
\hline $\begin{array}{c}\text { Core } \\
\text { Upstream \& }\end{array}$ & 16 & 30 & 15 & 5000 & 0.4 & 0 & $1.16 \times 10^{-9}$ \\
downstream shell & 18 & 34 & 1 & 15000 & 0.35 & 13 & $9.26 \times 10^{-8}$ \\
$\begin{array}{c}\text { Filters \& } \\
\text { transition }\end{array}$ & 18 & 36 & 3.5 & 10000 & 0.3 & 7 & $2 \times 10^{-4}$ \\
\hline
\end{tabular}


shows the parameters of Mohr-Coulomb elastic-plastic model for various zones of the dam [10].

\section{Instrumentation results}

In earth dams, with the premise that other conditions are similar in all points, the most critical section regarding stability is always the highest section. Further, most of the stresses, displacements, and pore water pressures usually take place in this section. As seen in Figure 1, since there are three sections in Siah Sang Dam in which they have set up instruments and it is not possible to analyze all these sections within the limited duration of the present research, the researcher will only present the stress-strain behavior in critical sections. Clearly, if the behavior of the dam in critical sections is understood accurately, this behavior could be generalized to all sections of the dam.

\subsection{Evaluations of instrumentation results and dam behavior}

\subsubsection{Vertical displacement}

To measure the displacement of the dam in profile B according to Figure 2, two tubes of inclinometers are installed in the downstream and upstream of the dam. The initial position of the casing is established in a survey taken with the inclinometer probe. Ground movement causes the casing to move from its initial position. The rate, depth, and magnitude of this displacement are calculated by comparing data from the initial survey with those from subsequent surveys. In Figure 3, vertical displacement amounts of the core in accordance with the dam's height are observable when the dam was constructed in six different time intervals. According to the graph, December 2006 is the date when the construction of the dam ended, and the maximum vertical displacement in the last reading
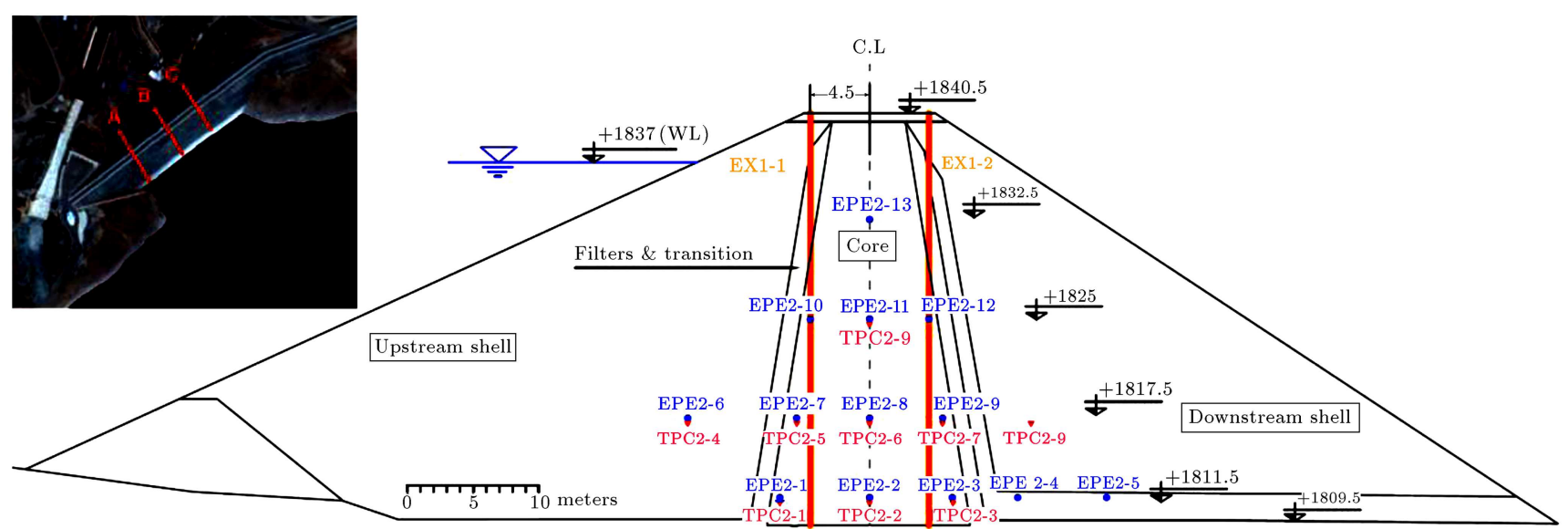

Figure 1. The plan view of Siah Sang Dam and arrangement of instruments in section B (critical section) [9].

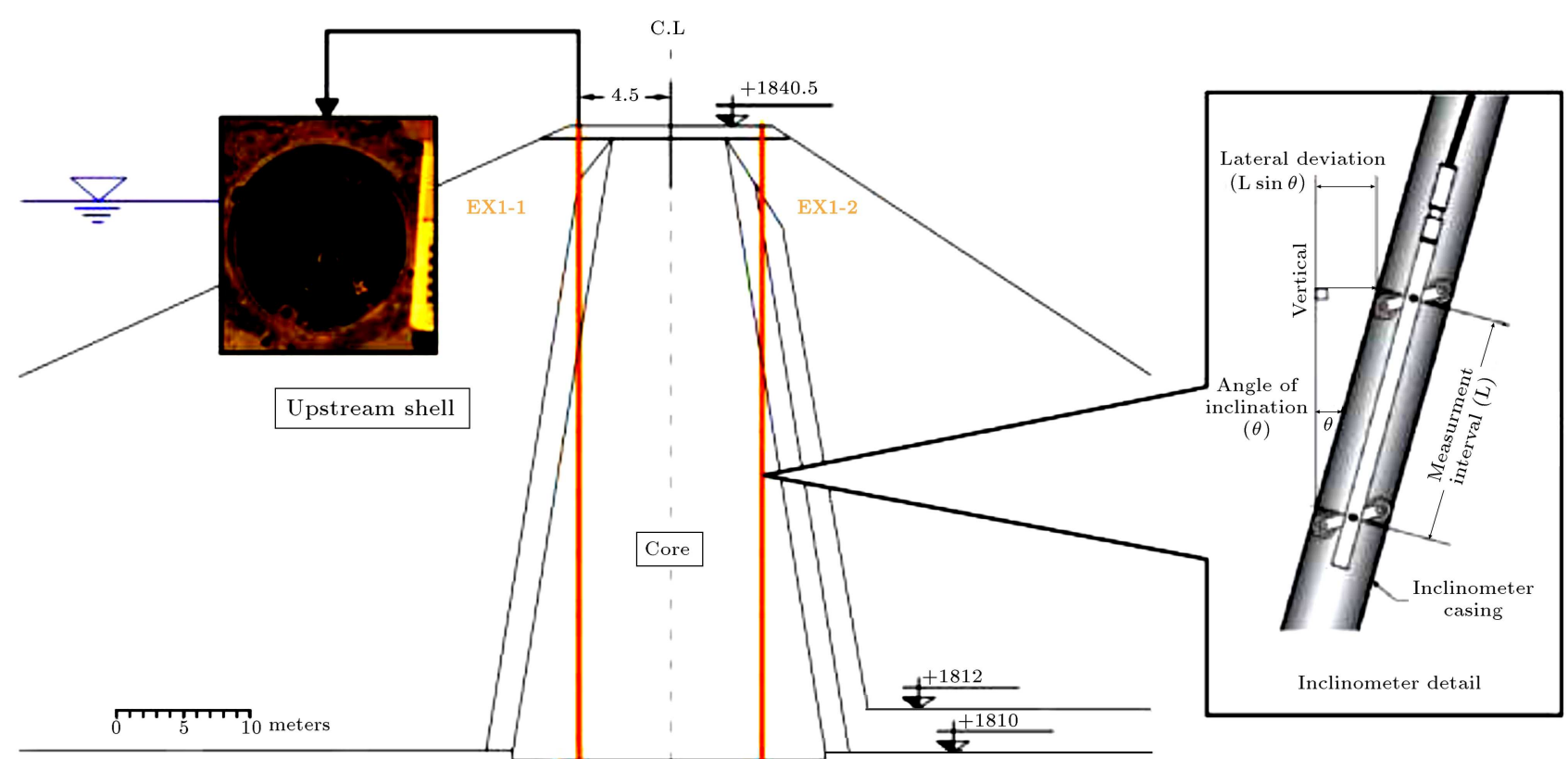

Figure 2. The arrangement of Inclinometers and their details in Siah Sang Dam [9]. 


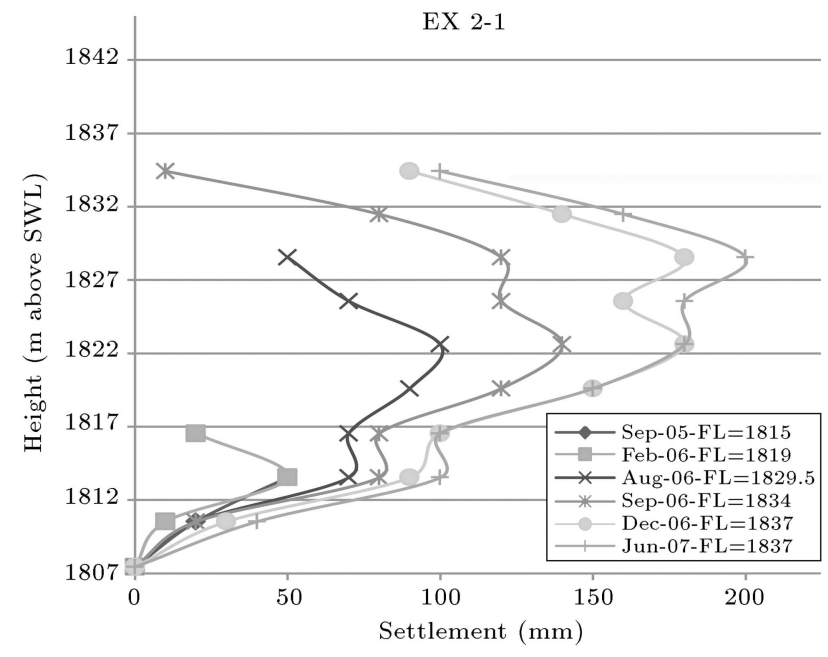

Figure 3. Upstream central core vertical displacement in accordance with dam's height in different times (measured values are depicted).

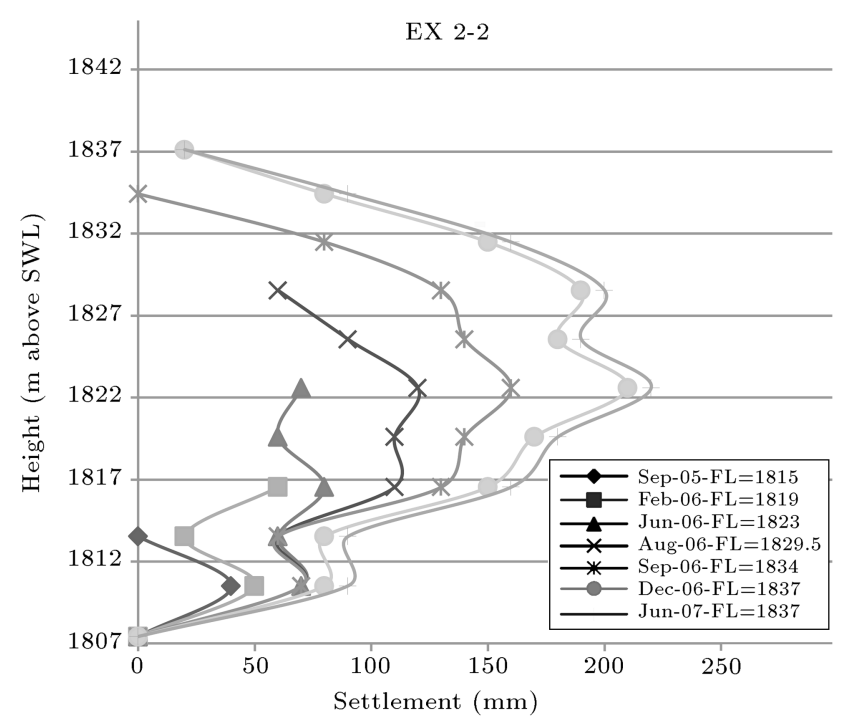

Figure 4. Downstream central core vertical displacement in accordance with height in different times (measured values are depicted).

on this date was equal to 18 centimeters. The initial impounding of Siah Sang Dam also began in the January of 2007 , and then vertical displacement in the June of 2007 was 20 centimeters. It was observed that from the initial impounding to the dam exploitation, which took approximately 6 months, the vertical displacement was only 2 centimeters. This vertical displacement is $10 \%$ of the total vertical displacement of the dam, while $90 \%$ of the vertical displacements was 18 centimeters which took place in the construction time as seen in the graph at some points in time. In addition, in Figure 4, the vertical displacement amounts are presented from the vertical displacement meter tubes in downstream in accordance to the levels in seven intervals. On the date when the hard operation of earth-filling was finished
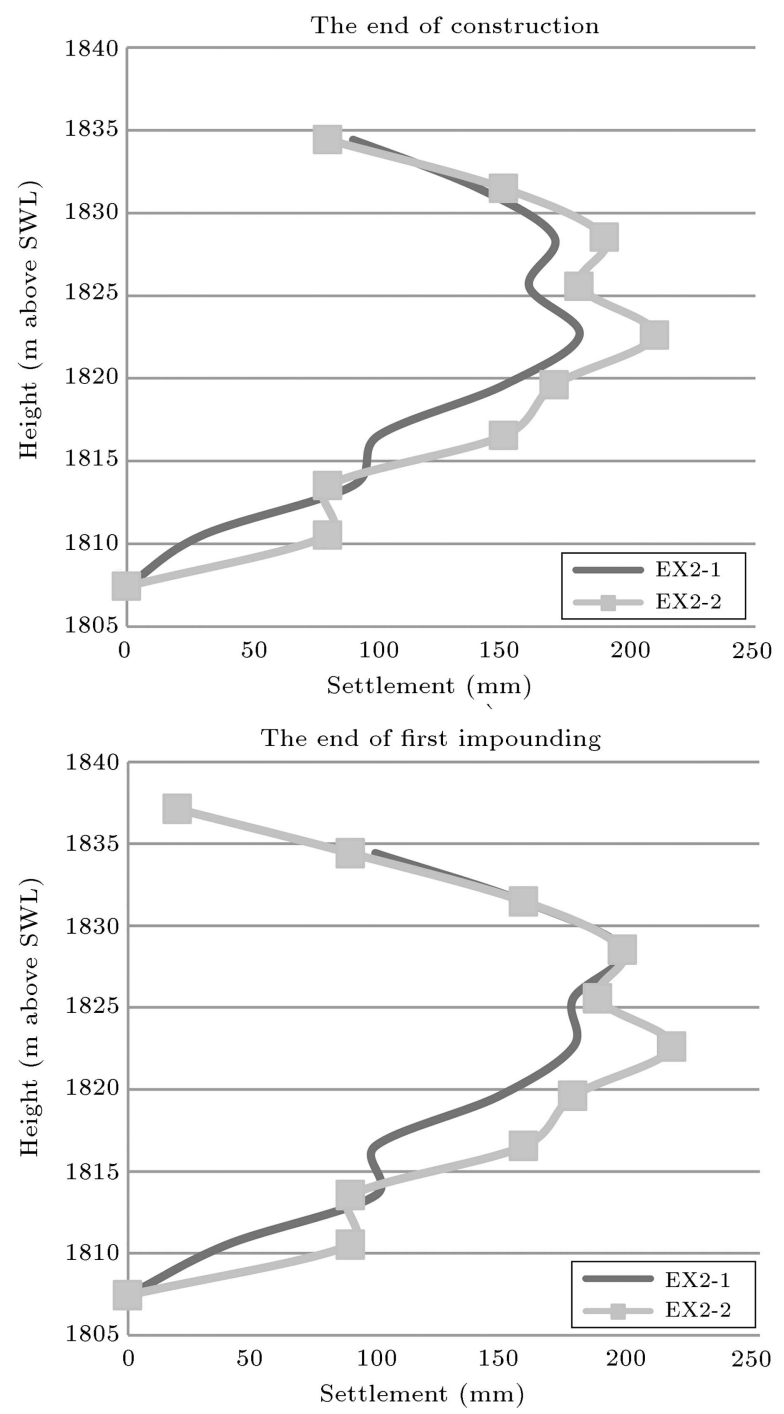

Figure 5. Vertical displacement in different heights in central core upstream and downstream (measured values are depicted).

(December 2006), maximum vertical displacement was 21 centimeters, located in the 15 meters of the height of the body of the dam, whereas this amount during impounding was just 1 centimeter.

Figure 5 compares vertical displacement amounts at the end of construction operation (December 2005) in 2 inclinometer tubes. As seen, the difference between core vertical displacements of upstream and downstream is not significant, and that is due to the difference between behavioral characteristics and compressibility of the materials of the core, filter, drainage, and shell. Considering the materials of the upstream, the downstream and central core are similar, and the difference between the vertical displacements in the upper part of the dam is very little. It also shows vertical displacement amounts 6 months after the beginning of the initial impounding (June 2007). The important point is the increase of the upstream 
shell vertical displacement in comparison to the downstream. The reason for this is the hydrostatic pressure of water on the upstream shell, causing more vertical displacement.

\subsubsection{Vertical stress}

Total pressure cells are installed in three levels as seen in Figure 6 in 1810.5, 1817.5, and 1825. These cells have been installed in a bunch of 3,5 , and 1 , respectively. Figure 7 shows the changes in total vertical stress in the pressure cells installed in 1810.5 level in accordance with earth filling. vertical stress changes in the process is steady and in tune with the progress of dam construction and fill height.

In Figure 8, there are changes in the vertical stress in the width of the core and upstream and downstream filters in the first level at different points in time. As it can be seen, with an increase in the levels of earth filling, the stress level in all widths of the core and filter

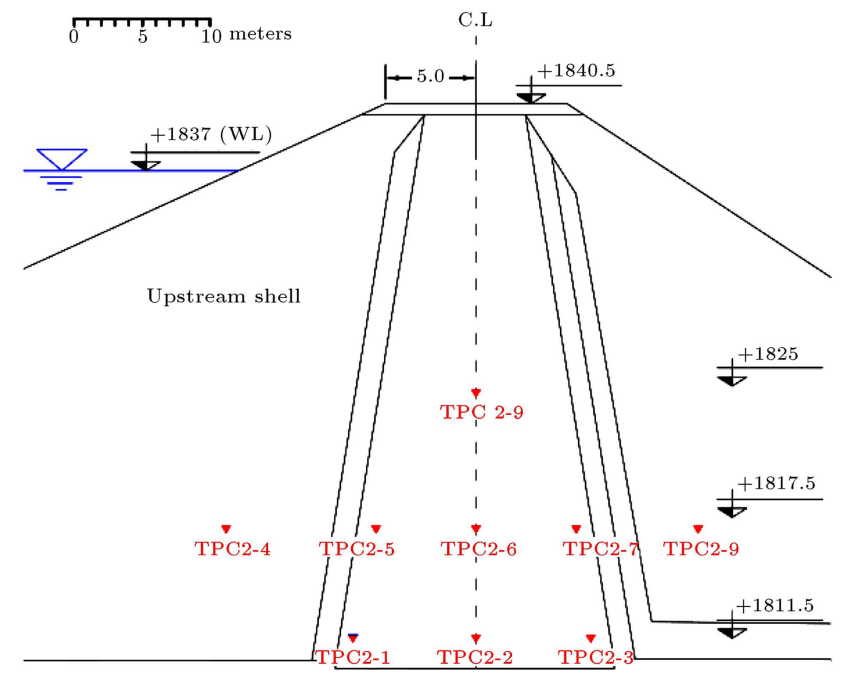

Figure 6. Total pressure measurement cells in different levels [9].

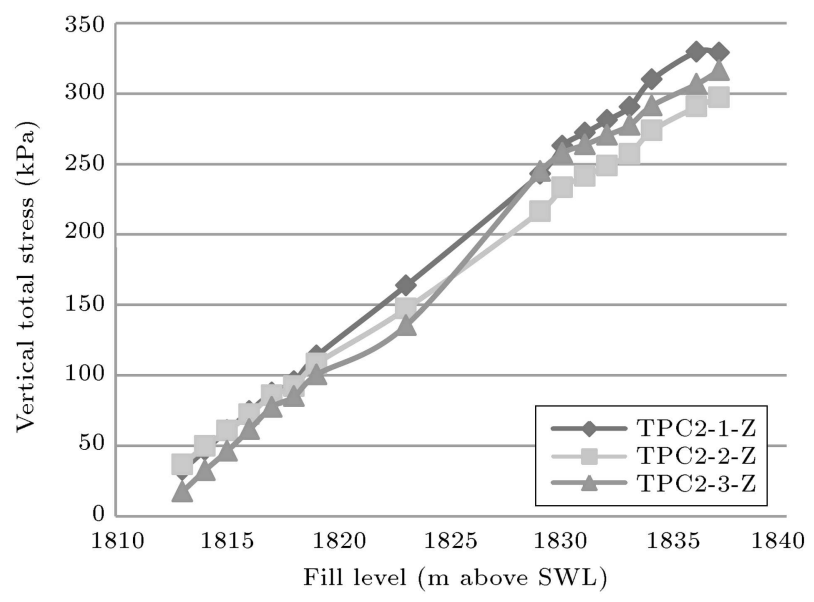

Figure 7. Changes in the total vertical stress in the pressure cells installed in the first level in accordance with time (measured values are depicted).

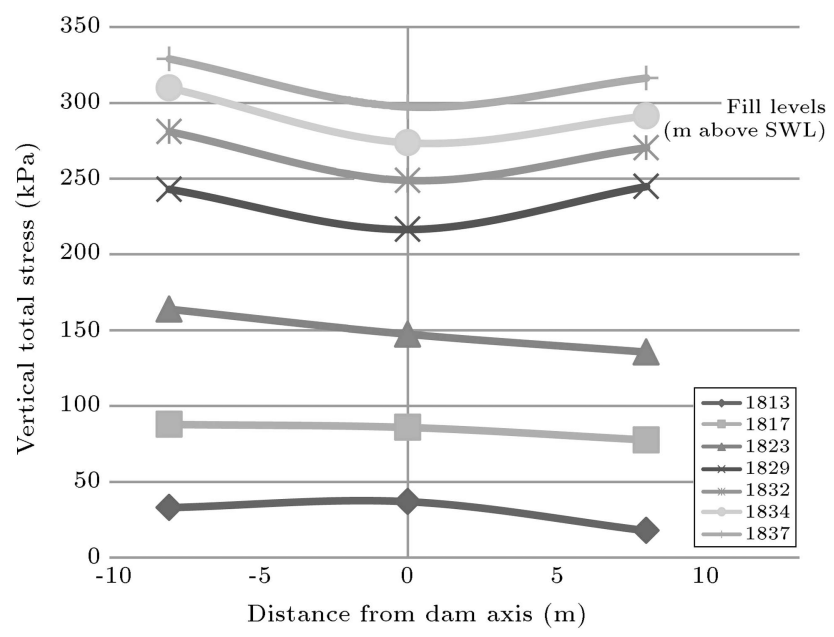

Figure 8. Changes in total vertical stress in the width of the dam body in the first level of different fill levels (measured values are depicted).

increases. The maximum stress, most of the times, is related to TPC2-1 pressure cell, which is located within 8-meter upstream of the dam axis inside clay whose amount at the end of the construction operation is 325 kilopascals.

\subsubsection{Arching ratio}

Shell materials, including rockfill and gravel, were stiffer than the materials used in the core. Difference of elasticity modulus between these two kinds of materials made various tendencies to vertical displacement. In addition, the friction between the core and shell materials caused a transfer of stress from the core to the shell, which could create a low-stress area in the core. This phenomenon is called arching in earth dams. Eq. (1) presents the arching ratio:

$$
A_{r}=\frac{\sigma_{v}}{\gamma \cdot h}
$$

where $\sigma_{v}$ is the vertical total stress $(\mathrm{kPa}), \gamma$ is the unit weight $\left(\mathrm{kN} / \mathrm{m}^{3}\right)$, and $h$ is the embankment height $(\mathrm{m})$ $[11,12]$. Since core is softer than shell, load transfer occurs from core to shell. As a result of this action, pore water pressure can become more than total stress within core. This action may make cracks due to excessive water pressure. These cracks are called hydraulic fracturing making holes from upstream to downstream. In addition, it causes a serious damage to the body of the dam, possibly leading to the dam failure. The higher the $A_{r}$, the less the arching phenomenon in the core, and the lower the probability of hydraulic fracturing would be.

In Figure 9, the changes in the ratio of vertical stress to the load, or to put it another way, the arching ratios in the width of the core and the filters in the first level $(+1811.5)$ in the 21- and 26-meter fill heights are shown towards the end of construction operation. 


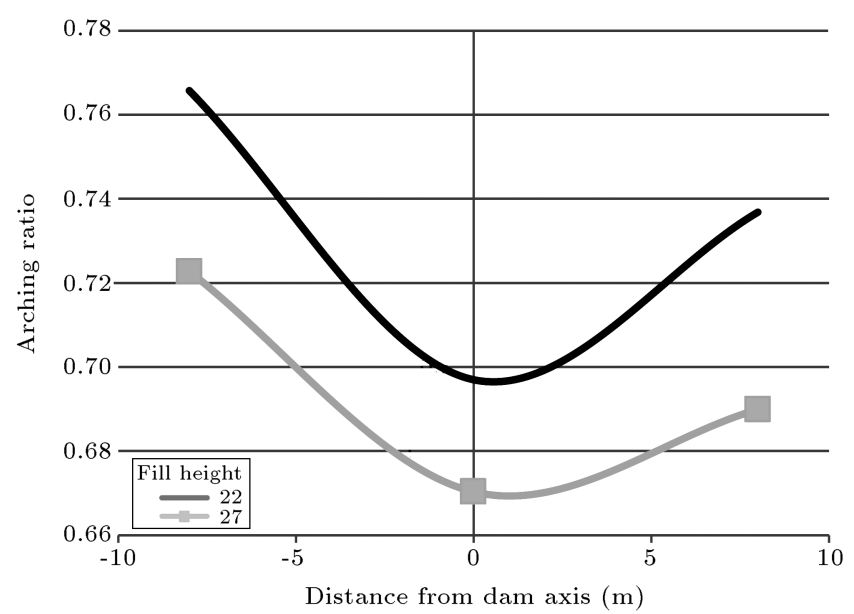

Figure 9. Changes in arching ratio of the width of the dam body in the first level in different fill height (measured values are depicted).

As seen, the most critical arching ratio in 21-meter fill height was about 0.7 . This issue indicates the fact that only 69 percent of the load weight on the core in this fill level is transferred to the materials underneath it, and 31 percent of the rest will be transferred to the shell and side filters of the core. As seen, 26-meter fill height of Siah Sang Dam, i.e. the most critical arching, decreases 0.67 with the difference that the arching ratio in the upstream areas increases and even reaches 0.72 ; however, in the downstream areas, this amount is just under 0.69. It is notable to compare ratios obtained by arching ratios of Iran's largest dams including Molla Sadra earth Dam with 72-meter height whose critical arching ratio is 0.45 and Gavoshan earth Dam with 125-meter height whose critical arching ratio is 0.52. Therefore, the more the arching ratio is, the less the created arching will be. We reach this conclusion that Siah Sang Dam will have no problem regarding hydraulic fracturing [13,14]. In addition, it should be noted that the bulk density of the core material providing arching ratio in different fill heights is $17.4 \mathrm{kN} / \mathrm{m}^{3}$.

\section{Numerical analysis}

Siah Sang Dam was modeled in 15 layers. The height of the earth-filling layers, with regard to the execution time, was defined to be between 1.5 to 2 meters. First, the cofferdam was modeled with regard to the time it was constructed, and then the layers were modeled. After constructing each layer and analyzing it, its displacements on the layer became zero. One should consider that the thickness of every layer should be one element; otherwise, the patterns of the changes in the vertical shapes of the body of the dam in the numerical model would be as disorganized curves. Siah Sang Dam impounding was done in 3 layers similar to its construction, and the height of the layers was between 7 and 9 meters. Each layer's impounding was carried out considering the height code of the water behind the dam, which was obtained by instruments. The first total impounding of the dam was done in 6 months. It should be noted that, in the numerical analysis, the rocky foundation was not modeled due to the main reasons such as its little settlement during construction ( 0.5 centimeters), low permeability of $1 \times 10^{-6} \mathrm{~m} / \mathrm{s}$ approximately, and concrete slab at the bottom of the clay core and its thickness reaching 50 centimeters; all these add to the reasons why modeling the foundation was avoided to accelerate analysis.

As seen in Figures 10 to 14, the results of the

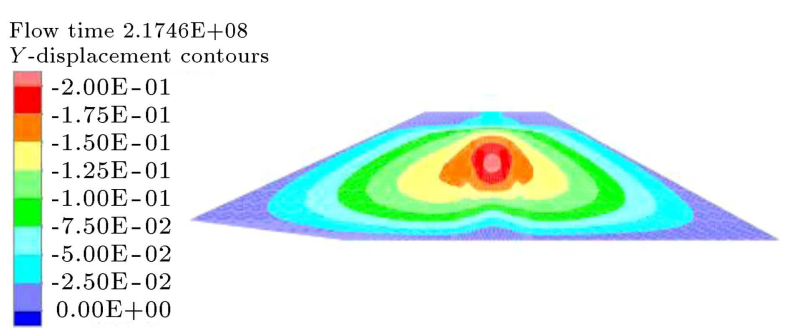

Figure 10. Vertical displacement of the dam (before starting the initial impounding).

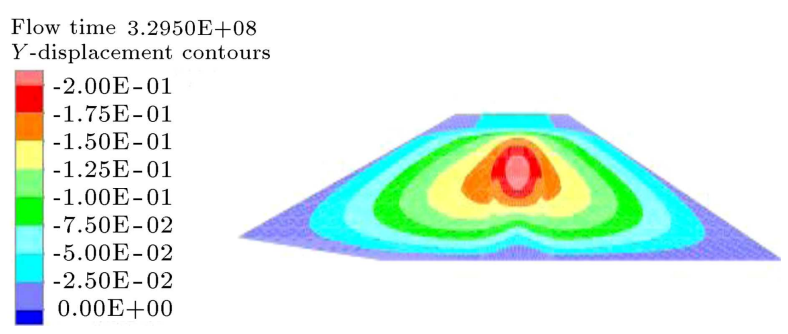

Figure 11. Vertical displacement of the dam (in the end of the first impounding).

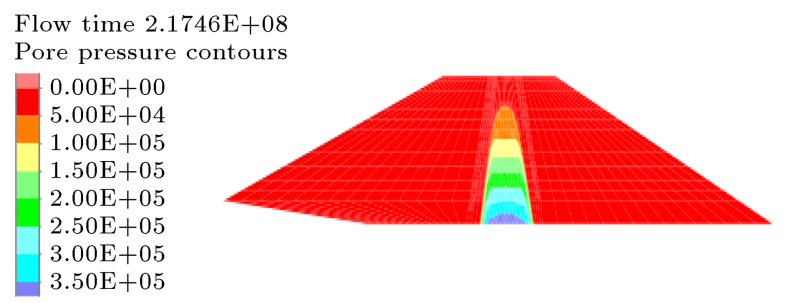

Figure 12. Pore water pressure of the dam (before starting the initial impounding).

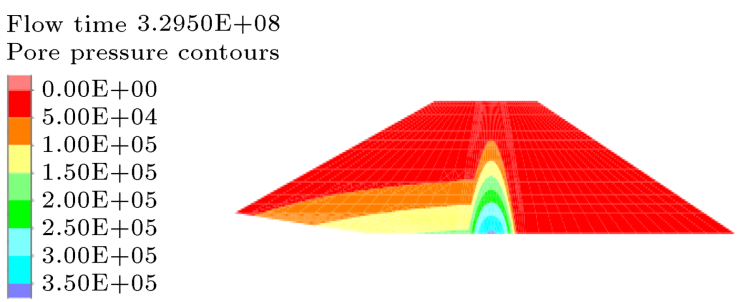

Figure 13. Pore water pressure of the dam (in the end of the first impounding). 
Flow time $2.1746 \mathrm{E}+08$

YY-stress contours

$-4.50 \mathrm{E}+05$

$-4.00 \mathrm{E}+05$
$-3.50 \mathrm{E}+05$

$3.00 \mathrm{E}+05$

$2.50 \mathrm{E}+05$

$-2.00 \mathrm{E}+05$

$1.50 \mathrm{E}+05$

$1.00 \mathrm{E}+05$

$-5.00 \mathrm{E}+04$

$0.00 \mathrm{E}+00$

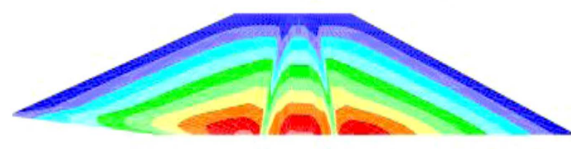

Figure 14. Dam's vertical stress level curve (before starting the initial impounding).

analysis are presented in 2 phases of the impounding of the dam. These phases include 27 meters of the fill before the beginning of the first impounding and at the end of first impounding.

The numerical analysis was done using FLAC software [15], and Mohr-Coulomb elasto-plastic model was used for the rockfill, filters, and earth-fill cores. The limitations of using such a simplistic model were recognized, but the main purpose of the analysis was to evaluate the stress conditions within the embankment and then to use the stresses in the analysis and interpretation of the monitored deformation records. In addition, for the first impounding analysis, the Justo method was used separately in unloading the lower layers due to submerging [4]. Considering impounding effect, the inner friction decreases the angle coefficient of the material, which was imagined to be $20 \%$ regarding the technical literature $[16,17]$. Decreasing coefficient of Young's modulus was also imagined to be $50 \%$ with regard to the carried-out studies $[18,19]$.

The steady-state seepage calculation was performed after the completion of the staged construction. Steady-state seepage of the dam for a $25 \mathrm{~m}$ water level was then performed without interaction with mechanical equilibrium. The final state of static equilibrium, called initial stress state, of the dam was then computed again after the steady-state seepage was reached.

\subsection{Examining the degree of accuracy of the number of elements in the results of numerical analysis}

The degree of the accuracy of the number of elements was analyzed many times since the regression analysis operations were carried out on the numerical analyses, and numerical computations were required. Two types of models were generated for that. The properties of the materials and their geometric shape are in accordance with Siah Sang Dam. The first sample seen in Figure 15 has a coarse mesh size and 750 elements, and the number of its layers is equal to that of the elements in the vertical direction in the numerical computation in time of construction, meaning that its vertical displacements will be equal to zero after every layer is constructed. Like the real construction time, the vertical displacement of all the elements will be zero once again.

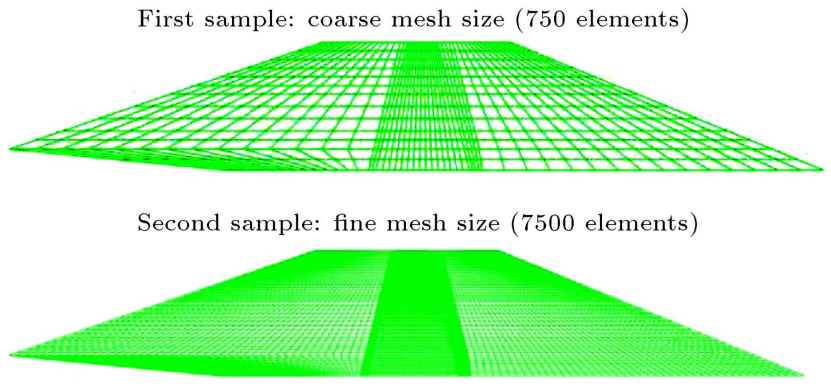

Figure 15. The first and second samples' meshing.

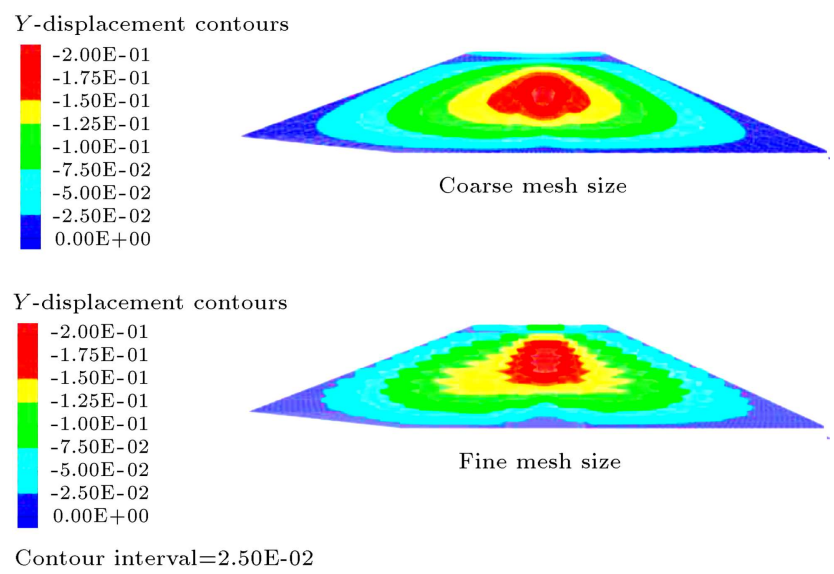

Figure 16. Vertical displacement of the first and second samples.

The second sample has a fine mesh size and 7500 elements. The time the program needs to run is very long for the second sample. The number of its layers is 15 at the time of construction, like the first sample. The difference between them, however, is that each layer has a number of rows of vertical elements on top of each other and is run after each layer; only the top element's vertical displacement will be equal to zero. This will lead to the vertical displacement, or the dam vertical displacement results will be disorderly and fluctuated. Figure 16 shows the difference between vertical displacements in the first and second samples.

In addition, examining the accuracy degree of the number of elements in the results of the numerical analysis made it clear that making the elements coarse and decreasing their number from 7500 to 750 elements will increase the ratio of the total vertical stress and pore water pressure values up to 2 and 3 percent, respectively, and will decrease vertical displacement to 4 percent. Nevertheless, the first sample or coarse mesh was also used in order to accelerate the computations and to better show the changes in the vertical displacements.

\subsection{Comparing the instrumentation and numerical results}

The evaluation will be completed in a case in which a back analysis is carried out in order to control the 


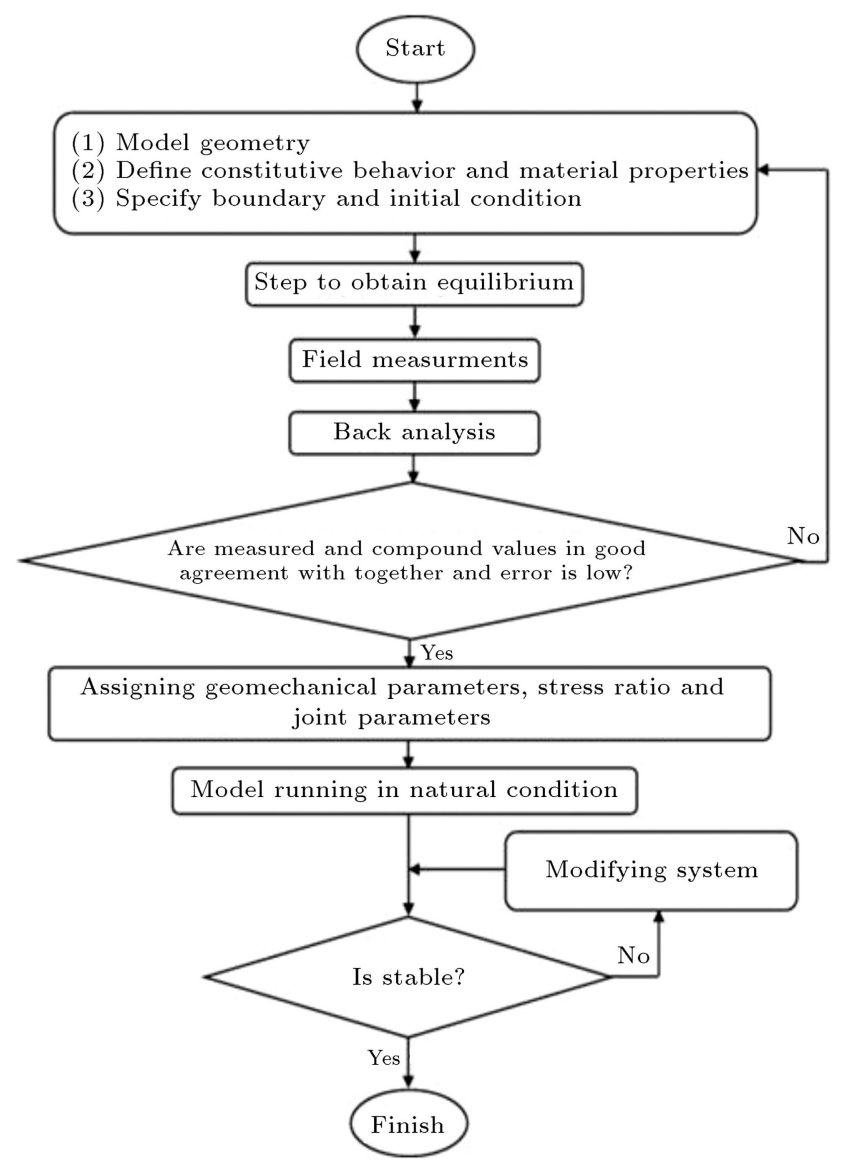

Figure 17. Back analysis method and solution algorithm.

degree of the accuracy and the level of confidence of the measured behavior, since each of the measurements could be controlled through comparing it to the model obtained from the numerical model. This process and solution algorithm are described in Figure 17.

\subsubsection{Vertical displacement results}

The internal vertical displacements of the dam are categorized into three groups: vertical, horizontal, and rotational movements. vertical movements show the vertical displacements in terms of material weight, compaction, and consolidation of the dam body. Horizontal movements mainly refer to the upstream movements that occur during impounding in the dam storage due to faster reduction of the effective stress in the upstream materials than in other parts of the dam. Downstream movement occurs due to the horizontal water pressure of the dam storage. Furthermore, rotational movements that appear in the upstream and downstream slopes are due to lower shear strength of materials in the foundation or body of the dam. Using surveying points, inclinometers (vertical displacement tubes) and/or vertical displacement gauges are conventional ways to measure these deformations in earth dams. In this study, an evaluation was only made up of the results of the vertical displacements in the
Siah Sang Dam obtained from inclinometers because the readings related to horizontal displacements were not available due to poor archive in the early years of the dam construction by the consulting engineers of the project.

In Figure 18, the vertical displacement of the upstream height of the central core is compared considering the results obtained from instruments and the amounts from numerical modeling, respectively, in December 2006 (towards the end of the construction operation) and June 2007 (after the initial impounding). As observed, the analysis results are very close to reality in both times. Additionally, the downstream shell's vertical displacement obtained by the instruments and the amounts obtained by numerical modeling in the two mentioned times in the last section were compared. At the end of construction operation, these results were close to each other. After the initial impounding, the results in the lower part of the dam were convergent. In addition, the reason for the undulation of the measured maximum vertical displacements from instruments would be the differences in soil compaction and soil heterogeneity in different layers of dam, while they should be theoretically smooth.

The inclinometers' readings are compared with numerical models in relation to the vertical displacement changes in different levels of the dam in accordance with the time in Figure 19. As observed, tangible differences between them were only in lower layer $(10 \mathrm{~m})$ in relation to upper layer $(19 \mathrm{~m})$, which were close to each other. It also shows that the vertical displacements of the dam decreased significantly after 400 days (at the end of construction and at the start of initial impounding).

\subsubsection{Vertical stress results}

In Figure 20, the process of the appearance of the vertical stress in the piezometers located in the first level is shown in accordance with time. As observed, the analysis results are very close to reality, except for the differences between vertical stresses in numerical model with the reality taken place after construction in TPC2-1. These amounts are close to each other before initial impounding, while divergent during initial impounding. As expected, vertical stress increased the same way as the result of numerical analysis did; however, due to the broken piezometer, this amount remained steady in instruments' results. Furthermore, as demonstrated by the results in Figure 20, there is a difference between the observed and calculated vertical stresses in TPC2-2. The vertical stresses in the pressure cells are lower than those obtained by the numerical analysis. There are some reasons why the results are divergent after the initial impounding (after 400 days) in upstream of the central core. Calibration of the instruments for load and temperature 

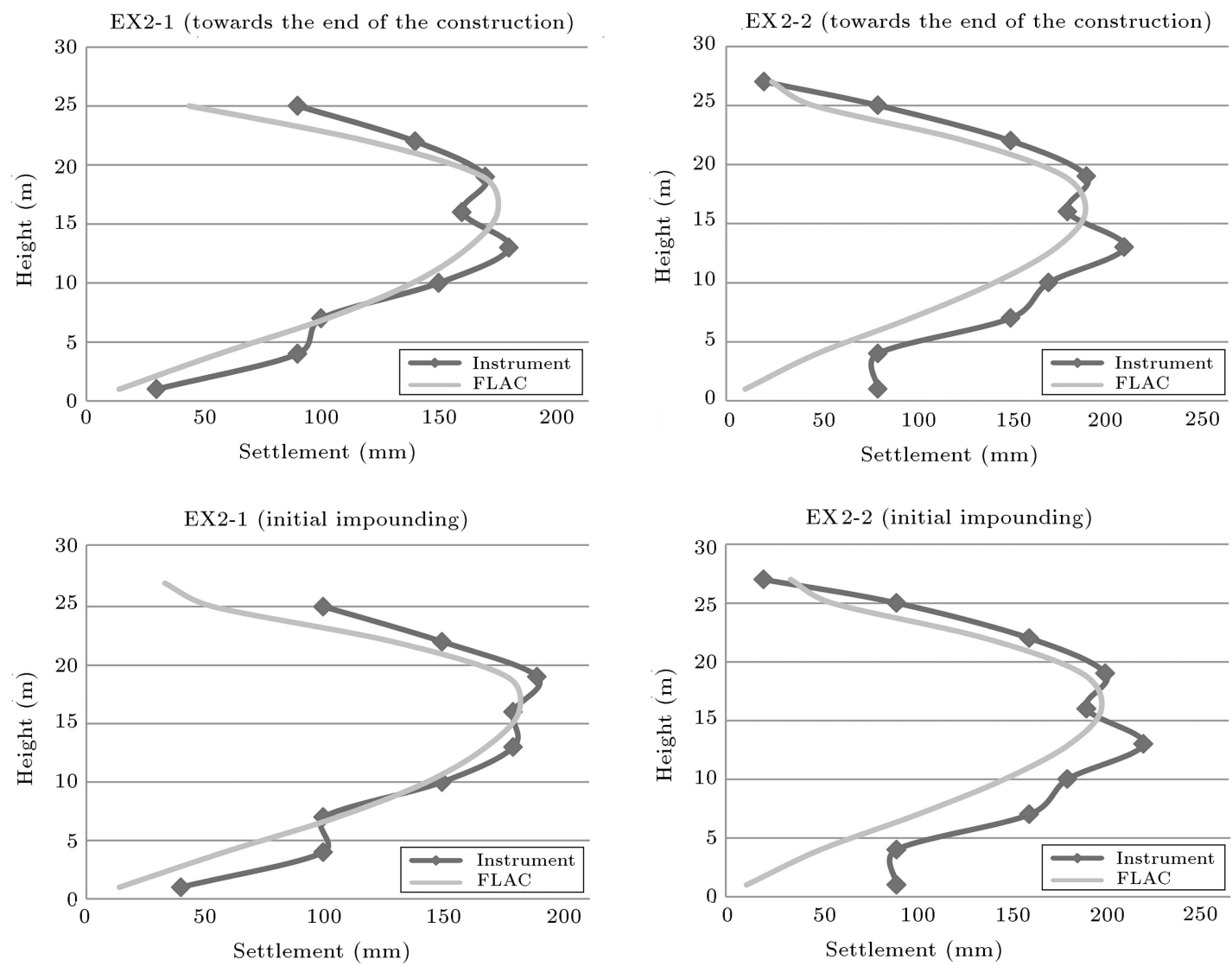

Figure 18. Comparing the results of the instruments and numerical modeling in relation to vertical displacement changes in the upstream (EX 2-1) and downstream (EX 2-2) heights of the central core towards the end of the construction operation and after the initial impounding.
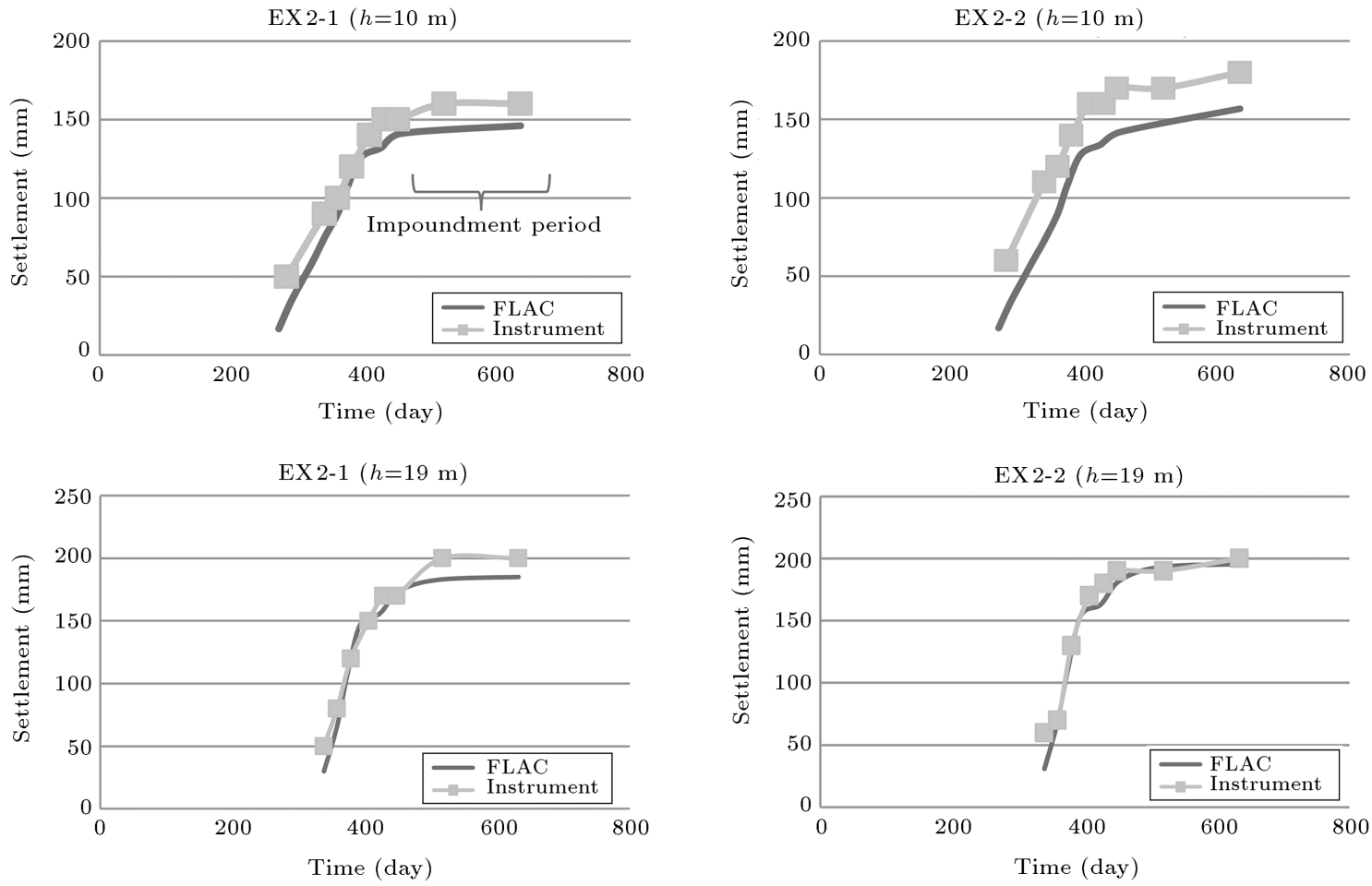

Figure 19. Comparing the results from the inclinometers and numerical model in relation to the vertical displacement changes in different levels of the dam with accordance to time. 

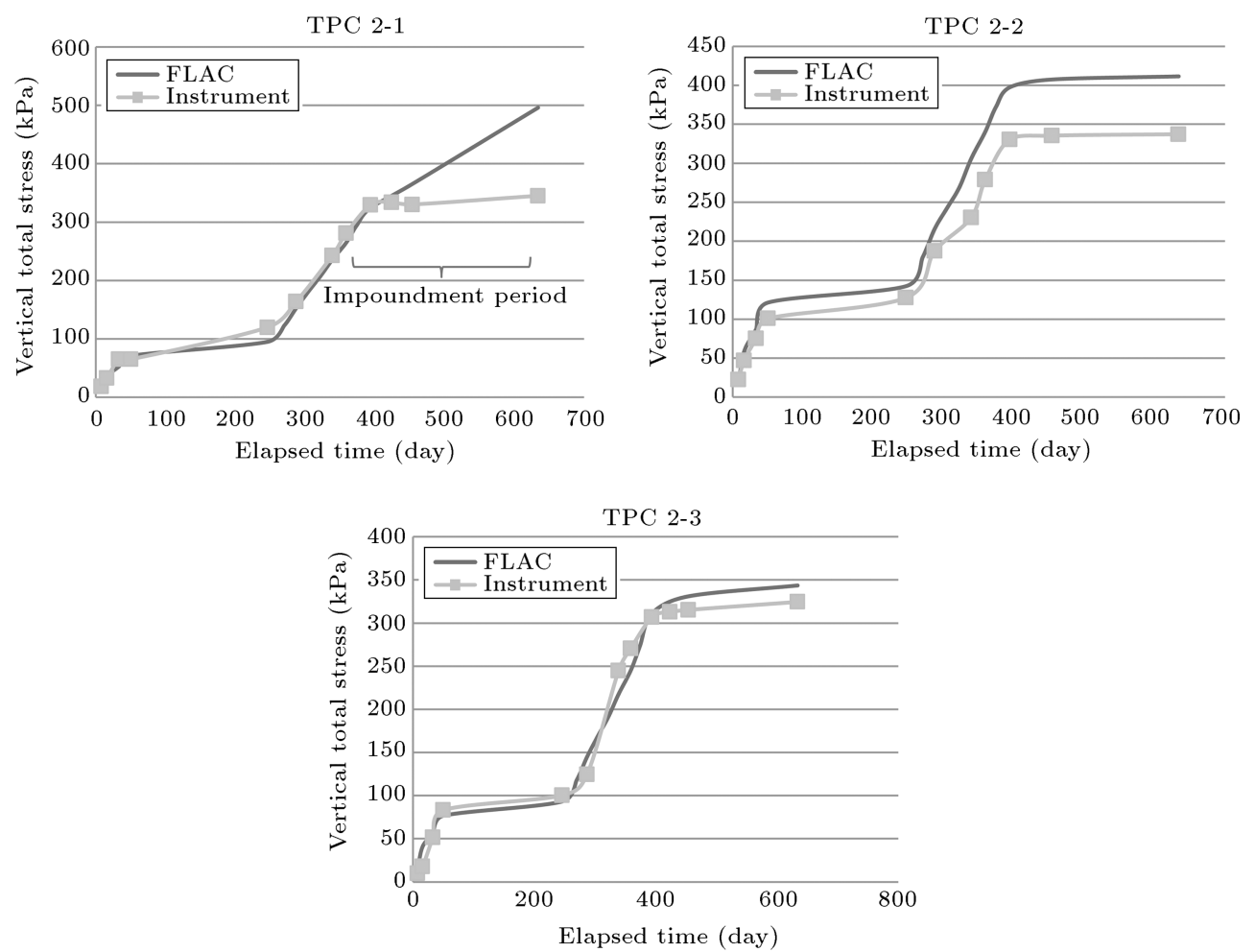

Figure 20. Comparing the measurement results and numerical model in relation with the total vertical pressure in the piezometers located in the first level.

is a difficult and expensive task, such that lack of calibration and destruction of instruments are assumed possible [20]. In addition, to prevent any damage to the pressure cells, the soil around the cells was compacted in a lower density in comparison to other parts of the core. Consequently, the reality of the soil stiffness in the body of the dam was mostly more than that around the cells.

\section{Summary and conclusion}

The purposes of this study are two-fold: (1) To make efforts to present a general evaluation of the function of the dam during construction and initial impounding through the data obtained by instruments from Siah Sang earth Dam and (2) To utilize modeling and carry out numerical analysis regarding the stress-strain behavior of the dam. The results obtained from this study are as follows:

- According to the numerical analysis, the vertical displacement results were consistent with the data recorded by the instruments in terms of both quality and quantity, showing that the maximum vertical displacement of the core was 18 centimeters at the end of construction. In the following 6 months after construction (initial impounding and exploitation period), the accumulative vertical displacement of the dam was 20 centimeters. It is clear that
$90 \%$ of the total vertical displacement of the dam took place during dam construction due to the clay core smashed in the wet side of the optimum moisture content. The aforementioned maximum vertical displacement showed that this value was at the rate of about $0.7 \%$ of the height of the dam;

- Total vertical stresses, extracted from the numerical analysis, proved to be in a tolerable trend with the data recorded at the pressure cells; however, there was a small difference in quantity. Inconsistency between the stresses obtained from the numerical analysis and pressure cells was mostly due to the local arching phenomena in the installation place of the pressure cells, which was as a result of inadequate compaction around these instruments that caused creating a low-stress zone;

- The arching ratios were calculated for the largest cross-section of Siah Sang Dam. The results demonstrated that the arching ratio in Siah Sang Dam was between 0.67-0.76, which placed the dam on the safe side in terms of hydraulic fracturing. In addition, examining the accuracy degree of the number of elements in the results of the numerical analysis made it clear that making the elements coarse and decreasing their number from 7500 elements to 750 elements will increase the ratio of the total 
vertical stress and pore water pressure values up to 2 and 3 percent, respectively, and decrease vertical displacement to 4 percent. Therefore, it is better to use the first sample or coarse mesh in order to accelerate the computations and to better show the changes in the vertical displacements.

Finally, it is worth mentioning that the behavior of this dam in its largest cross-section was reasonable in terms of vertical displacement and stresses at the end of construction and the first impounding.

\section{References}

1. Duncan, J.M. "State of the art: Limit equilibrium and finite-element analysis of slopes", A.S.C.E., Journal of Geotechnical Engineering, 122(7), pp. 577-595 (1996).

2. Kovacevic, N., Potts, D.M., and Vaughan, P.R. "Finite element analysis of a rockfill dam", Proc. 8th Int. Conf. Computer Methods \& Advances in Geomechs., Morgantown, West Virginia, 3, pp. 2459-2464 (1994).

3. Lambe, T.W. "Predictions in soil engineering", Rankine Lecture. Geotechnique, 23(2), pp. 149-202 (1973).

4. Justo, J.L. "Collapse: Its importance, fundamentals and modeling", In Advances in Rockfill Structures, Kluwer Academic Publishers, Netherlands, pp. 97-152 (1991).

5. Naylor, D.J. "Finite element methods for fills and embankment dams", Advances in Rockfill Structures E. Maranha das Neves, pp. 291-340 (1990).

6. Naylor, D.J. "Collapse vertical displacement some developments", Applications of Computational Mechanics in Geotechnical Engineering, Balkema, Rotterdam, pp. 37-54 (1997).

7. Eisenstein, Z. and Law, S.T.C. "Analysis of consolidation behaviour of Mica dam", A.S.C.E., Journal of the Geotechnical Engineering Division, 103(GT8), pp. 879-895 (1977).

8. Cavounidis, S. and Hoeg, K. "Consolidation during construction of earth dams", A.S.C.E., Journal of the Geotechnical Engineering Division, 103(GT10), pp. 1055-1067 (1977).

9. Zumr, D. and Císlerova', M. "Soil moisture dynamics in Levees during flood events-variably saturated approach", J. Hydrol. Hydromech., 58(1), pp. 64-72 (2010).

10. Technical Reports of Siah Sang Dam, Consulting Engineers Mahab Ghods (2007).

11. Terzaghi, K. "Stress distribution in dry and in saturated sand above a yielding trap-door", in Proceeding of First International Conference on Soil Mechanics and Foundation Engineering, Cambridge, Massachusetts, pp. 307-311 (1936).
12. Terzaghi, K., Theoretical Soil Mechanics, New York, John Wiley and Sons (1943).

13. Nikkhah, M., Attaie, S., Tavakoli, H., and Hasan, Y. "Evaluation of instrumentation records of the dam body and foundation if embankment mollasadra dam during construction and first stage impounding", ICOLD 75th Annual Meeting, Saint Petersburg, Russia (2007).

14. Rashidi, M. "Evaluation of the behavior of earth and rockfill dams during construction and first impounding using instrumentation data and numerical modeling", M.S. Thesis in Civil Engineering, Sharif University of Technology (2012).

15. FLAC version 4, USER MANUAL, Itasca Consulting Group, Inc (2002).

16. Alonso, E.E. and Oldecop, L.A. "Fundamentals of rockfill collapse", Proceedings of the Asian Conference on Unsaturated Soils, Singapore, Balkema, Rotterdam, pp. 3-13 (2000).

17. Soroush, A. and Aghaei, A. "Uncertainties in mechanical behavior of rockfills during first impounding of rockfill dams", 73rd Annual Meeting of ICOLD, Tehran, Iran, Paper No. 186-S5 (2005).

18. Soboya, J.R.F. and Byrne, P.M. "Parameters for stress and deformation analysis of rockfill dams", Canadian Geotechnical Journal, 30(4), pp. 690-701 (1993).

19. Varadarajan, A. and Sharma, K.G. "Venkatachalam K and Gupta A K testing and modeling two rockfill materials", Journal of Geotechnical and Geoenvironmental Engineering, ASCE, 129(3), pp. 206-217 (2003).

20. Dunnicliff, J. and Green, G., "Geotechnical Instrumentation for Monitoring Field Performance", Ed; A Wiley Inter-Science Publication (1988).

\section{Biographies}

Mohammad Rashidi received his BSc degree in Civil Engineering from University of Tabriz and his MSc degree in Civil Engineering from Sharif University of Technology. He is currently a PhD student at the University of Texas at El Paso. His research interests include numerical analysis, monitoring and instrumentation, computational mechanics and geomechanics, dam and geotechnical Engineering, pavement, geosynthetics, and road construction. He has presented and published several papers in various international conferences and journals.

Mokhtar Heidari received his MSc degree from University of Sistan and Baluchestan, Zahedan, Iran in Hydraulic Structures. His main research interests are dam engineering, ground water, hydraulic structures, seepage, and numerical analysis.

Gholamreza Azizyan received his BSc degree in Civil 
Engineering from University of Sistan and Baluchestan in 1985, MSc degree from University of Tehran, Iran in Hydraulic Structures in 1991, and PhD degree in the same field from University of Newcastle upon Tyne, UK in 2009. He is currently an Assistant
Professor of Civil Engineering at University of Sistan and Baluchestan, Iran. His main research interests are hydraulic engineering, water resources engineering, hydraulic structures, river mechanics, and groundwater. 